\title{
Transcriptional regulation of a pair-rule stripe in Drosophila
}

\author{
Stephen Small, ${ }^{1}$ Rachel Kraut, ${ }^{1}$ Timothy Hoey, ${ }^{2}$ Rahul Warrior, ${ }^{3}$ and Michael Levine ${ }^{1}$ \\ Department of Biological Sciences, Fairchild Center, Columbia University, New York, New York 10027 USA
}

\begin{abstract}
The periodic, seven-stripe pattern of the primary pair-rule gene even-skipped (eve) is initiated by crude, overlapping gradients of maternal and gap gene proteins in the early Drosophila embryo. Previous genetic studies suggest that one of the stripes, stripe 2 , is initiated by the maternal morphogen bicoid (bcd) and the gap protein hunchback $(h b)$, while the borders of the stripe are formed by selective repression, involving the gap protein giant $(g t)$ in anterior regions and the Krüppel $(K r)$ protein in posterior regions. Here, we present several lines of evidence that are consistent with this model for stripe 2 expression, including in vitro DNA-binding experiments and transient cotransfection assays in cultured cells. These experiments suggest that repression involves a competition or short-range quenching mechanism, whereby the binding of $\mathrm{gt}$ and $\mathrm{Kr}$ interferes with the binding or activity of $b c d$ and $h b$ activators at overlapping or neighboring sites within the eve stripe 2 promoter element. Such short-range repression could reflect a general property of promoters composed of multiple, but autonomous regulatory elements.
\end{abstract}

[Key Words: Pair-rule gene; Drosophila; pattern formation; stripe; short-range repression]

Received January 16, 1991; revised version accepted March 5, 1991.

Previous genetic screens have identified $\sim 50$ regulatory genes that control early development in Drosophila, and approximately half of these subdivide the embryo into a repeating series of segments (Lewis 1978; Kaufman et al. 1980; Nüsslein-Volhard and Wieschaus 1980). Many of the segmentation genes have been cloned and characterized (e.g., Laughon and Scott 1984; McGinnis et al. 1984), and the vast majority encode nuclear factors containing well-characterized DNA-binding motifs, including the homeo domain (Levine and Hoey 1988; Scott et al. 1989), zinc fingers (Rhodes and Klug 1988), the helixloop-helix (Murre et al. 1989), and the leucine zipper (Vinson et al. 1989). Each of these genes shows a unique pattern of expression in the early embryo and is active in a specific subset of cells (Akam 1987; Ingham 1988). It has been shown in numerous instances that the misexpression of a particular segmentation gene causes disruptions in the pattern of the embryo; sometimes, these phenotypes mimic other segmentation mutants (e.g., Struhl 1985).

Spatially restricted patterns of segmentation gene expression depend on a hierarchic series of gene interactions. The first step in this hierarchy is the establishment of crude gradients of maternal morphogens in unfertilized eggs and early embryos. Among these is the homeo box protein bicoid $(b c d)$, which plays a key role

Present addresses: ${ }^{1}$ Biology Department, Bonner Hall, University of California, San Diego, La Jolla, California 92093-0346 USA; ${ }^{2}$ Department of Molecular and Cell Biology, University of California, Berkeley, California 94720 USA; ${ }^{3}$ Roche Institute of Molecular Biology, Nutley, New Jersey 07110 USA. in the initiation of gap gene expression (Berleth et al. 1988; Driever and Nüsslein-Volhard 1988). Each of the five known gap genes is expressed in one or two broad domains that span several adjacent segment primordia (e.g., Gaul and Jäckle 1987; Pignoni et al. 1990). They are thought to control segmentation primarily through the regulation of the pair-rule genes which, in turn, initiate the expression of $\sim 10$ different segment polarity genes (for review, see Ingham 1988). This regulatory cascade occurs quite rapidly and culminates just $5 \mathrm{hr}$ after fertilization in the precise expression of the segment polarity genes within the limits of single cells in every segment primordium (e.g., DiNardo et al. 1985; Kornberg et al. 1985; Hooper and Scott 1989; Nakano et al. 1989).

A recurring theme of the segmentation hierarchy is the progressive refinement in the patterns of gene expression. At every step in the hierarchy a given segmentation gene makes a relatively sharp "on/off" choice in response to more crudely distributed regulatory products. Here, we present evidence that this refinement in expression involves the interactions of distinctive combinations and concentrations of regulatory factors with promoter sequences that have the properties of an on/off switch. In particular, we have examined the interaction of the gap genes with the pair-rule gene even-skipped (eve).

eve encodes a homeo box protein that is expressed in a series of seven transverse stripes along the length of the embryo that play a key regulatory role in the establishment of the metameric body plan (Harding et al. 1986; Macdonald et al. 1986; Frasch et al. 1987). The formation 
of the striped expression pattern involves a two-step process. First, it has been shown by promoter fusion studies that separate cis promoter elements direct the initial expression of individual stripes (spanning five to six nuclei). There is considerable evidence that this initial seven-stripe pattern is controlled by the broadly distributed, overlapping domains of the gap gene products. $\mathrm{Mu}$ tations in any of the gap genes lead to a severe disruption of the initial seven-stripe pattern (Frasch and Levine 1987; Driever and Nüsslein-Volhard 1988; M. Frasch, unpubl.). Later, the eve protein present within these initially broad stripes interacts with a distal enhancer element located between -5.9 and $-5.2 \mathrm{~kb}$ upstream from the transcription start site (Goto et al. 1989; Harding et al. 1989; Jiang et al. 1991), which helps refine the stripes so that each spans just two to three cells and shows anterior-posterior polarity by the onset of gastrulation (Lawrence et al. 1987; Frasch et al. 1988).

We present a model for the transcriptional regulation of the initiation of eve stripe 2. We have focused on this stripe because previous promoter fusion analyses and genetic studies have provided considerable information about the cis and trans components that participate in its localized expression. A truncated promoter containing $1.7 \mathrm{~kb}$ of eve $5^{\prime}$-flanking sequence is sufficient to drive the expression of a reporter gene (lacZ) within the limits of stripe 2 (Goto et al. 1989; Harding et al. 1989). A 480-bp internal deletion between -1.6 and $-1.1 \mathrm{~kb}$ abolishes expression (Goto et al. 1989). Potential transregulators of stripe 2 have been identified on the basis of examining the distribution of eve protein in all known segmentation mutants (Frasch and Levine 1987; Driever and Nüsslein-Volhard 1988; M. Frasch, unpubl.). These studies, as well as the tight linkage of the wild-type expression patterns, suggest that the gap genes hunchback (hb), giant (gt), and Krüppel $(K r)$ are the most likely candidates for regulators of stripe 2 expression. There is evidence that two of these, $h b$ and $K r$, directly regulate the expression of the stripe because they bind to closely linked sites in the stripe 2 promoter element (Stanojevic et al. 1989/. Here, we show that the leucine zipper protein $g t$ (E. Eldon and V. Pirrotta, pers. comm.) binds to stripe 2 sequences as well. Surprisingly, we also found several binding sites for the maternal morphogen $b c d$. The $g t$ - and $K r$-binding sites overlap or are closely linked to the $h b$ and $b c d$ sites. Transient cotransfection assays suggest that $b c d$ and $h b$ activate transcription by binding to stripe 2 sequences. This activation is repressed by the coexpression of either $K r$ or $g t$, and DNA binding is required for repression by either protein, suggesting that $g t$ and $K r$ repress expression through a competition or short-range quenching mechanism. We discuss the implications of such short-range repression with respect to the evolution of complex promoters.

\section{Results}

A model for the genetic control of eve expression at stripe 2

The wild-type limits of $h b$ (Tautz et al. 1987), $K r$ (Rosen- berg et al. 1986), and gt (Mohler et al. 1989) expression suggest that they have a direct role in regulating the initiation of eve expression within the limits of stripe 2 (Fig. $1 \mathrm{~A}-\mathrm{C}$ ). The anterior domain of $h b$ expression completely overlaps with eve stripe 2 (Fig. 1A; Stanojevic et al. 1989; Warrior and Levine 1990). bcd is expressed in a gradient that extends beyond the anterior $h b$ domain (Driever and Nüsslein-Volhard 1988) and encompasses the region of the stripe. The anterior limit of the $K r$ pattern abuts the posterior border of stripe 2 (Stanojevic et al. 1989; Fig. 1B|, while gt abuts the anterior border of the stripe (Fig. 1C).

The expression patterns for the four putative regulators of stripe 2 are summarized in Figure 1D. In this model, the maternal morphogen $b c d$ and the gap gene $h b$ activate eve expression in the stripe 2 region, and the borders of the stripe are formed by repressive interactions by $g t$ anteriorly and $K r$ posteriorly. This model is supported by previous studies of eve expression patterns in various mutants (Frasch and Levine 1987): (1) eve stripe 2 is greatly reduced or missing in $h b^{-}$embryos; (2) stripe 2 appears to be fused with stripe 3 in $\mathrm{Kr}^{-}$embryos; and (3) stripe 2 appears to be fused with stripe 1 in $\mathrm{gt}^{-}$ embryos. Furthermore, Goto et al. (1989) have shown that stripes 2 and 3 are fused in $\mathrm{Kr}^{-}$embryos carrying a heterologous promoter construct that selectively expresses stripes 2,3 , and 7 .

These studies suggest that the domain of expression in stripe 2 expands in $\mathrm{gt}^{-}$and $\mathrm{Kr}^{-}$embryos but cannot rigorously rule out the possibility that the expansion derives from the adjacent stripes ( 1 in $g t^{-}$and 3 in $\mathrm{Kr}^{-}$). To distinguish among these possibilities, we examined an eve promoter-lacZ gene fusion (Fig. 2B) that expresses lacZ only at the positions of stripes 2 and 7 (Fig. 2C). In $\mathrm{Kr}^{-}$embryos the fusion gene is expressed in a broad band rather than a narrow stripe, due to an expansion of its posterior border (Fig. 2D). Similarly, $g t^{+}$gene activity seems to be important for the specification of the anterior stripe border because there is an anterior expansion of $1 a c Z$ expression in $\mathrm{gt}^{-}$embryos (Fig. 2E). Stripe 2 expression is lost or greatly reduced in $b c d^{-}$and $\mathrm{hb}^{-}$embryos, suggesting that these genes exert a positive effect on its expression (data not shown). We have not examined the expression of the stripe $2-1 a c Z$ gene fusion in any other segmentation mutants, because the earlier studies (Frasch and Levine 1987) indicated that none of the other genes were required for the initiation of stripe 2 expression. For example, stripe 2 appears normal in knirps and tailless mutants, as well as in maternal mutants that disrupt the torso or nanos morphogenetic organizing centers.

\section{DNA-binding assays}

The type of genetic studies described above fail to distinguish between direct and indirect regulatory interactions. As a first step toward determining whether the interactions might be direct, we performed DNA-binding assays using stripe 2 sequences and $b c d, h b, g t$, and $K r$ proteins. Previous studies have identified a number of 

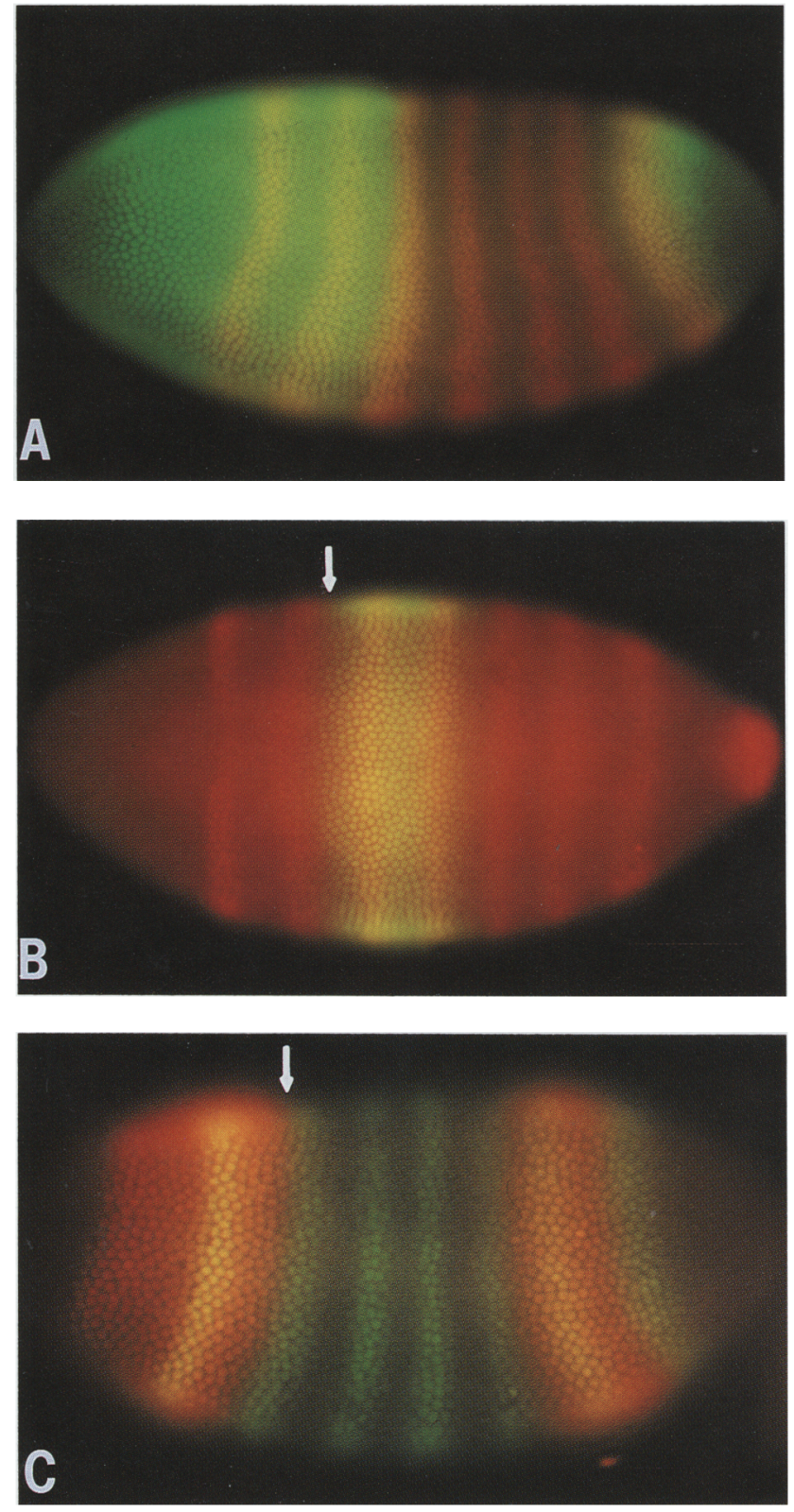

$h b$ - and $K r$-binding sites (Stanojevic et al. 1989). In this study we have overexpressed full-length, nonfusion $b c d$ and gt proteins in Echerichia coli (Studier and Moffatt 1986) and used these to perform systematic DNase I footprint assays across the eve stripe 2 element. We focused primarily on promoter sequences extending from about -1700 to -800 bp because previous studies suggested that this region plays a particularly important role in stripe 2 expression (Goto et al. 1989). Furthermore, studies on $h b$ and $K r$ indicate a lack of binding sites in proximal regions of the promoter (Stanojevic et al. 1989). Examples of the binding experiments are presented in Figure 3.

Figure 3A shows the results of a DNase I protection assay, using affinity-purified $b c d$ protein and a $\sim 406-b p$

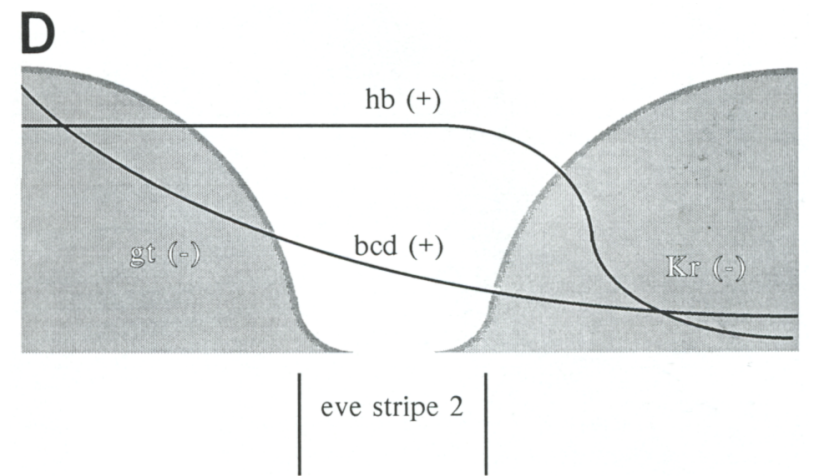

Figure 1. Wild-type expression patterns of putative regulators of eve stripe 2. (A). Wild-type embryo stained with a mixture of eve (red) and $h b$ (green) antibodies (regions of overlap appear yellow). This embryo and the other embryos shown here and in Fig. 2 are oriented with anterior to the left and dorsal up. The anterior domain of $h b$ extends to the posterior border of stripe 3 . The posterior $h b$ domain overlaps the seventh eve stripe. $(B)$ Wild-type embryo stained with a mixture of eve (red) and $K r$ (green) antibodies. The broad central domain of $K r$ expression extends from the posterior border of eve stripe 2 to the anterior border of stripe 5. (C) Wild-type embryo stained with a mixture of eve (green) and $g t$ (red) antibodies. The anterior domain of $g t$ expression extends to the anterior limit of stripe 2 . The posterior $g t$ domain extends from the posterior border of stripe 5 to the anterior border of stripe 7 (see also Mohler et al. 1989. (D) Summary of the trans regulation of eve stripe 2 . The approximate expression patterns of the $b c d$ and $h b$ activators are represented by heavy black curves. Together, these proteins coincide with a broad domain where the stripe 2 element can be activated. The borders of the stripe (represented by the vertical lines at the bottom) are established by repressive interactions mediated by $g t$ (anterior border) and $K r$ (posterior border).

DraIII-Ball DNA fragment, which extends from about $-1.3 \mathrm{~kb}$ to $-900 \mathrm{bp}$ upstream from the start site. Strong protection is observed for the sequence TCGAAGGGATTAGG located at about $-1285 \mathrm{bp}$, which includes an 8 out of 9 match with the bcd core consensus sequence (GGGATTAGA) determined by Driever and Nüsslein-Volhard (1989). A second bcd-binding site is seen at about $-1190 \mathrm{bp}$ and also contains an 8/9 match with the consensus (GGGATTAGC).

Figure 3B shows the DNA-binding activity of the $g t$ protein. In this experiment a 349-bp RsaI-StyI DNA fragment (located between approximately -1.5 and -1.2 $\mathrm{kb})$ was ${ }^{32} \mathrm{P}$-labeled on the noncoding strand and incubated with increasing amounts of the $g t$ protein. Sequence studies done by E. Eldon and V. Pirrotta have 
A.

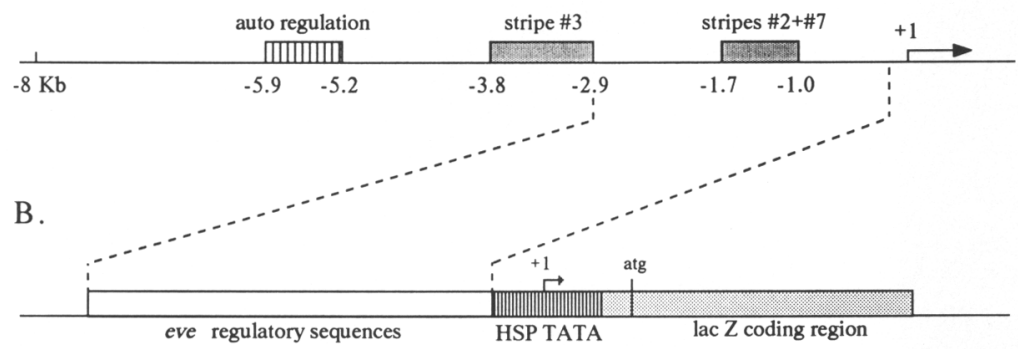

Figure 2. Summary of eve promoter elements and expression of the stripe 2 element. (A) The horizontal line represents a map of the eve promoter. Three essential cis regulatory elements were identified in earlier studies (Goto et al. 1989; Harding et al. 1989): an auto regulatory element located between -5.9 and $-5.2 \mathrm{~kb}$, the stripe 3 initiation element between -3.8 and $-2.9 \mathrm{~kb}$, and the stripe 2 and 7 elements located between -1.7 and $-1.1 \mathrm{~kb}$. The arrow and +1 indicate the transcription initiation site. $(B)$ Diagram of a heterologous fusion promoter that expresses stripe 2 in P-transformed embryos. eve $5^{\prime}$ sequences from $-2.9 \mathrm{~kb}$ to $-42 \mathrm{bp}$ were inserted into the HZ50 P-element expression vector (Hiromi and Gehring 1987). HZ50 contains the hsp 70 minimal promoter attached to the bacterial lacZ-coding sequence. $(C)$ Embryo collected from a P-transformed line containing the fusion promoter shown in $B$. Expression of the $l a c Z$ reporter gene was detected by staining with an anti- $\beta$-galactosidase antibody. Staining is restricted to stripe 2 ; none of the other eve stripes are observed (including 7). (D) Stripe 2 expression in a $\mathrm{Kr}^{-}$ embryo. The eve-lacZ fusion gene shown in $B$ was crossed into a $K r^{\circ}$ (Redemann et al. 1988) mutant background. A broad band of lacZ expression is observed due to an expansion in the posterior limit of the stripe. (E) Stripe 2 expression in a $\mathrm{gt}^{-}$embryo. The eve-lac $Z$ fusion gene shown in $B$ was crossed into a $g t^{\text {YA82 }}$ (Wieschaus et al. 1984) mutant background. A broader band of lac $Z$ expression is observed due to expansion of the anterior border of the stripe.
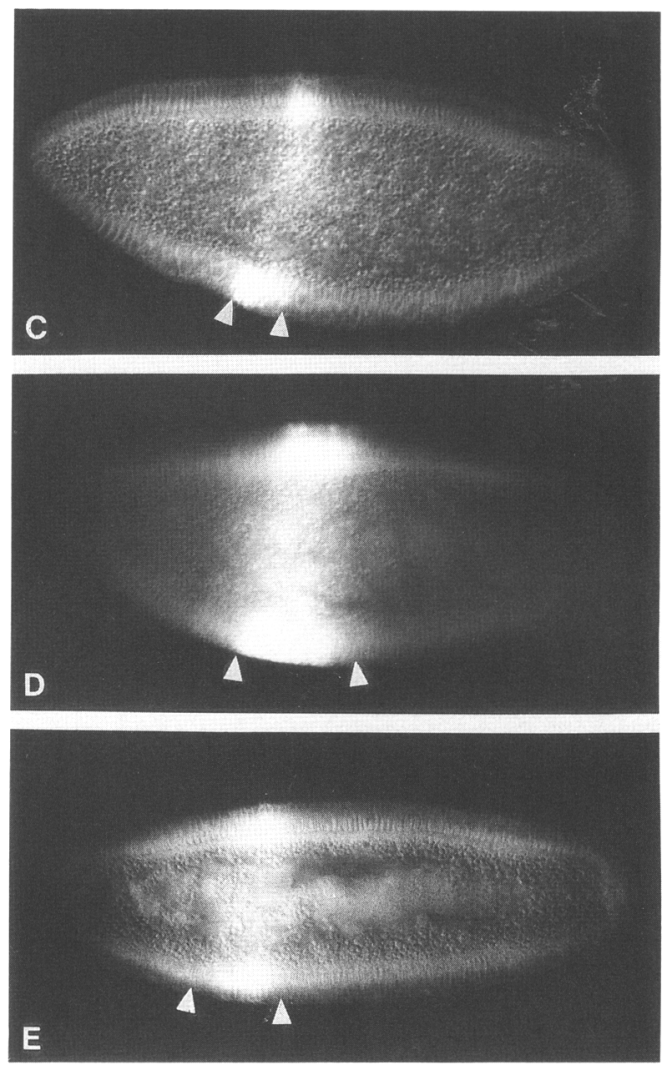

shown that $g t$ contains a basic leucine zipper (pers. comm.). Two sites of DNase I protection are observed, one located at about $-1430 \mathrm{bp}$ and a second at -1350 bp. The distal site completely encompasses one of the five $b c d$-binding sites present in the stripe 2 element. Among the three $g t$-binding sites that we have identified, the one located at $-1350 \mathrm{bp}$ contains the highest affinity for the protein. Interestingly, the core sequence within the protected region possesses weak dyad symmetry and shares 12 out of 20 identities with the consensus sequence of the prototypic leucine zipper protein C/EBP (Fig. 3D; Vinson et al. 1989). The weaker gt-binding sites at -1430 and -1110 bp share 10 out of 20 identities.

The locations of $b c d-, h b-, g t-$, and $K r$-binding sites are summarized in Figure 4. There are a total of 17 highaffinity binding sites between -1700 and $-800 \mathrm{bp}$, and 12 of these map within the 480-bp region that is essential for expression (from -1550 to $-1070 \mathrm{bp}$ ). As shown previously (Stanojevic et al. 1989), there are a total of three $K r$ sites and one $h b$ site within this interval. The current study led to the identification of five $b c d$ sites and three $g t$ sites. Of the $12 \mathrm{bcd}-\mathrm{hb}-, \mathrm{gt}-$, and $\mathrm{Kr}$-binding sites present within this region, 8 are found in two clusters of $\sim 50$ bp each (see Fig. 4B). Each of these clusters includes binding sites for two putative activators and two overlapping repressors (Fig. 4C). The proximal cluster (at about $-1.1 \mathrm{~kb}$ ) contains a high-affinity binding site for each of the putative stripe 2 regulators, whereas the distal cluster contains two $b c d$ activation sites rather than one $b c d$ site and one $h b$ site.

The tight linkage of activator- and repressor-binding sites suggests that $g t$ and $K r$ might define the stripe 2 borders through a competition mechanism. Figure $3 \mathrm{C}$ shows footprint assays with the $b c d$ and $K r$ proteins using a DNA fragment that contains two copies of the 54bp proximal cluster (see summary of sequence in Fig. $4 \mathrm{C}$ ). Increasing amounts of the $b c d$ and $\mathrm{Kr}$ proteins result in sites of protection that overlap extensively, and DNAbinding studies with mixtures of the two proteins indicate that they cannot co-occupy these closely linked sites (data not shown). This close linkage probably results from the similar sequences recognized by the $b c d$ and $K r$ proteins; their core consensus-binding sites share 5 out of 10 matches (Driever and Nüsslein-Volhard 1989; Stanojevic et al. 1989; Triesman and Desplan 1989|.

bcd and hb function multiplicatively to activate stripe 2 promoter sequences in cotransfection assays

To determine how the $b c d, h b, K r$, and $g t$ proteins might regulate stripe 2 expression, transient cotransfection assays (Han et al. 1989) were done by using reporter plasmids that contain sequences from the stripe 2 promoter element. In the experiments described here, a single copy 


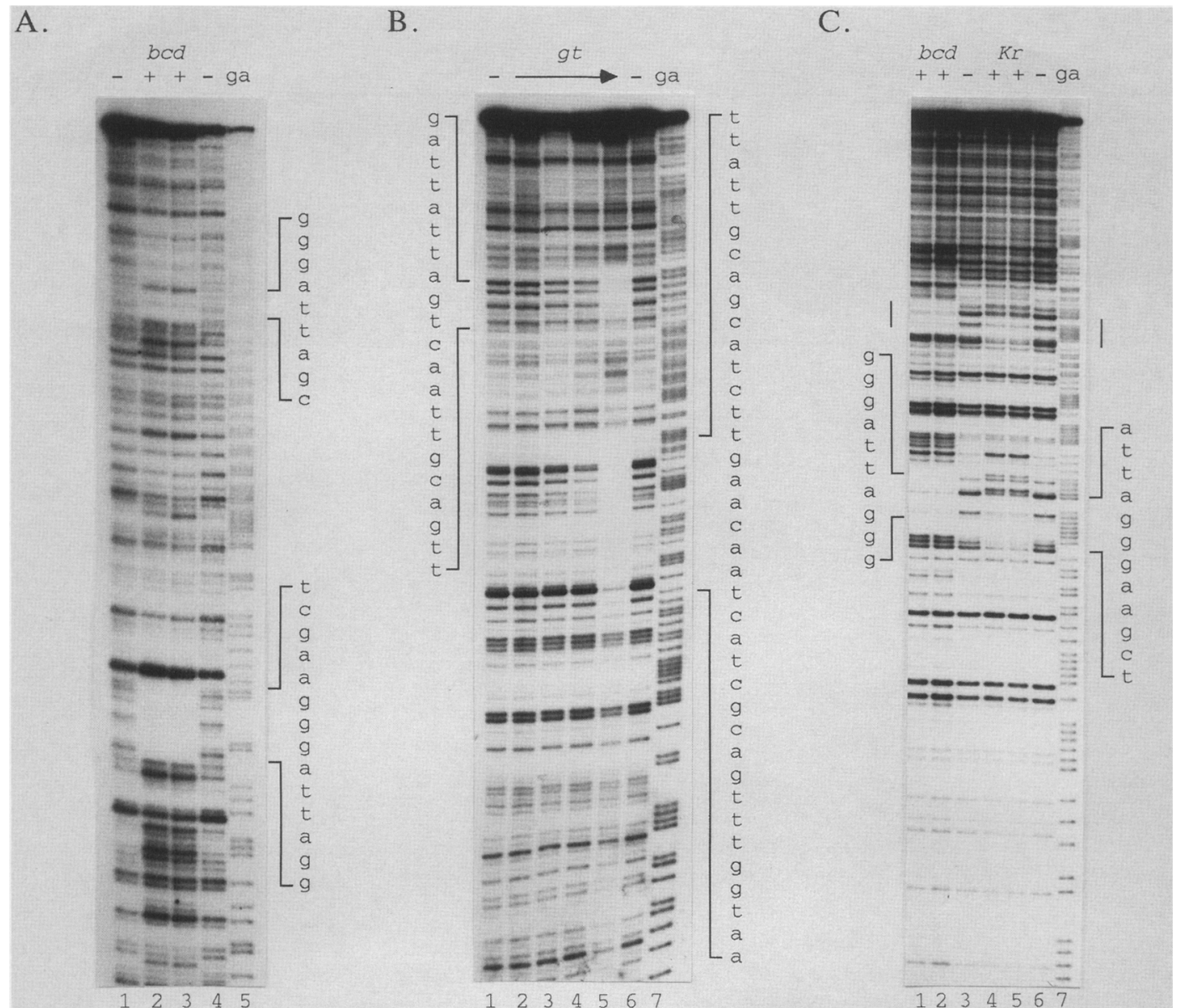

D.

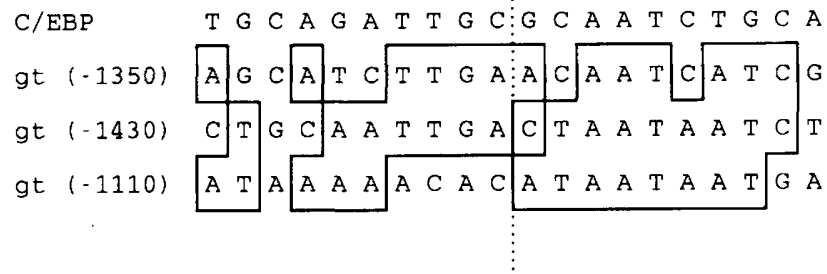

Figure 3. Footprint assays with eve stripe 2 sequences and $b c d, K r$, and $g t$ proteins. ${ }^{32}$ P-Labeled DNA fragments from the stripe 2 element were incubated with increasing amounts of full-length $b c d(A), g t(B)$, or $b c d+K r(C)$ protein made in bacteria. Protein-DNA complexes were partially digested with DNase I and electrophoresed on polyacrylamide-urea gels. (A) A 406-bp BalI-DraIII DNA fragment (see Fig. 4A) from the stripe 2 element was ${ }^{32} \mathrm{P}$-labeled and incubated with affinity-purified bcd protein (lanes 2 and 3). The two regions that are protected by $b c d$ are shown by the brackets to the right of the autoradiogram, along with their sequences. Note the appearance of hypersensitive sites that flank the protected regions. Lanes labeled - correspond to DNA-binding reactions with control extracts from bacteria lacking the $b c d$ expression plasmid. Lane ga shows the G + A sequence of the DNA fragment using the Maxam-Gilbert sequencing reaction. (B) A 349-bp StyI-RsaI fragment was ${ }^{32}$ P-labeled and incubated with increasing amounts of bacterial extract containing full-length gt protein (lanes 2-5). Two protected regions are shown by brackets, along with their sequences. (C) A 350-bp XbaI-KpnI DNA fragment containing two copies of the 54-bp proximal element was ${ }^{32} \mathrm{P}-\mathrm{labeled}$ at the $X b a I$ site and incubated with increasing amounts of affinity-purified bcd protein (lanes 1 and 2) or $K r$ extract (lanes 4 and 5). Two protected areas (one in each copy of the 54-base element) were detected for each protein. The limits and sequence of the bcd-binding site is shown to the left of the autoradiogram, and the $K r$ site is shown to the right. Note that the protected regions overlap by at least $7 \mathrm{bp}$. (D) gt-binding sites are related to the C/EBP consensus sequence. Maximal alignments of the three gt-binding sites identified in this study. These are compared with the C/EBP consensus sequence of Landschulz et al. (1989). Sequence identities are indicated by the boxes. The numbers to the left indicate the locations of the binding sites relative to the transcription start site.

of each cluster of binding sites (distal and proximal) was placed in tandem upstream of the hsp 70 minimal promoter and attached to the bacterial chloramphenicol acetyltransferase (CAT) reporter gene (summarized in Fig. 5). Similar results were obtained with reporter plas- mids containing either the proximal or distal cluster in isolation (data not shown). The reporter plasmid shown in Figure 5 was used to transfect Schneider cells, together with expression plasmids containing the fulllength $b c d-, h b-, K r-$, and $g t$-coding sequence under the 

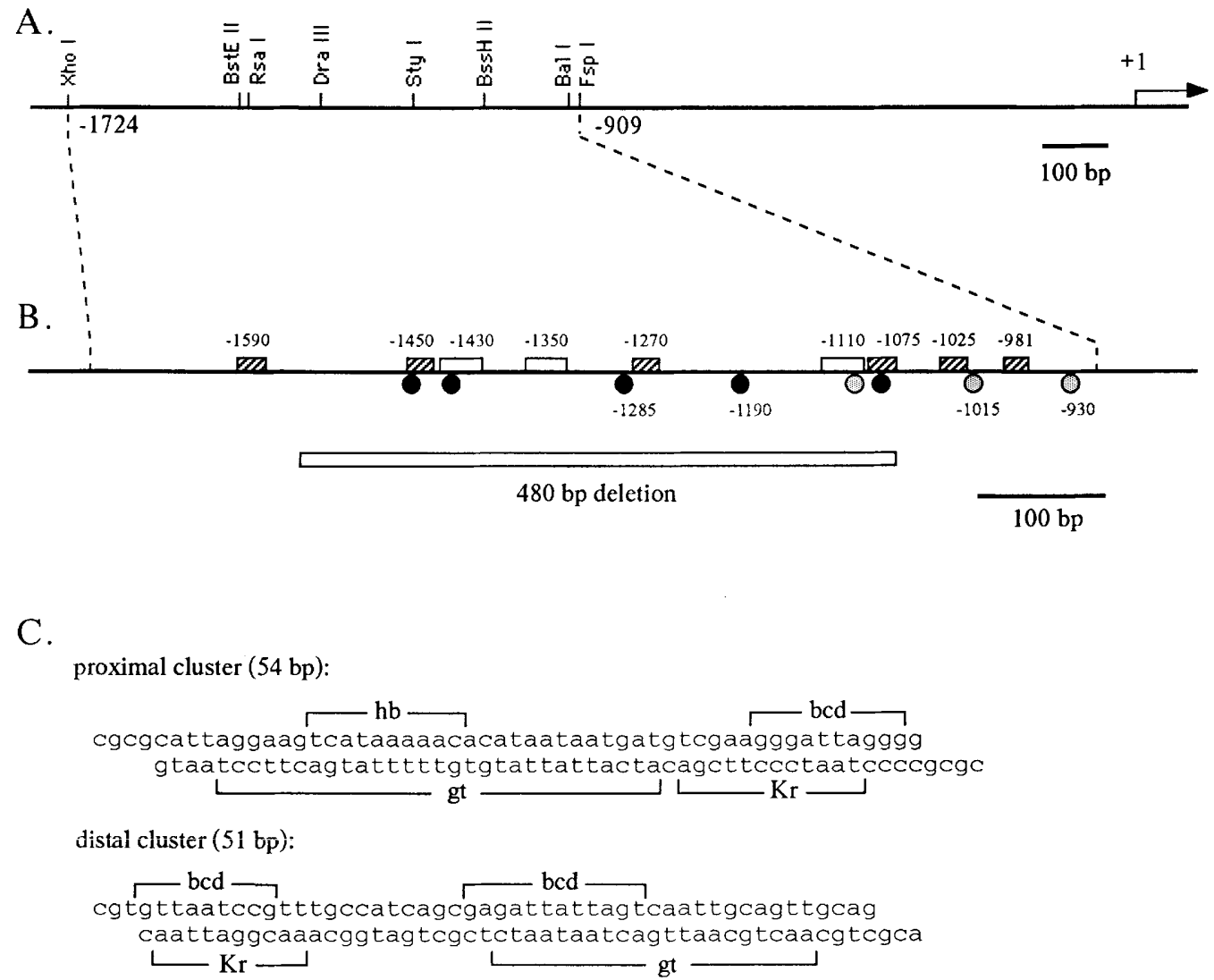

Figure 4. Summary of the $b c d-, h b-, K r-$, and $g t$-binding sites in the stripe 2 element. (A) Restriction map of the proximal region of the eve promoter. This is only a partial map showing some of the restriction sites relevant to the study. $(B)$ Schematic map of the DNA-binding sites. The locations of the $h b$ and $K r$ sites were reported previously (Stanojevic et al. 1989); the $b c d$ and $g t$ sites were identified in this study. The binding sites of activators $(b c d$ and $h b)$ are depicted as solid circles and stippled circles, respectively, below the line. Repressor sites $(K r$ and $g t)$ are shown as hatched boxes and open boxes, respectively, above the line. Note the two clusters of binding sites (at -1440 and -1090 ), where two activator sites overlap two repressor sites. The 480-bp region (from the BssHII site to the BstEII site) that is essential for expression of stripe 2 (Goto et al. 1989) is shown below the line. (C) DNA sequence of the proximal and distal clusters showing the limits of the binding sites based on footprint assays. Oligonucleotides used for cotransfection assays correspond to the sequences shown here (see Fig. 5).

control of the actin $5 \mathrm{C}$ promoter (Driever and NüssleinVolhard 1989). Each expression plasmid was tested separately; of the four, only the $b c d$ and $h b$ plasmids activated CAT to any significant extent. Increasing amounts of the actin- $b c d$ expression plasmid resulted in a progressive increase in CAT activity, which peaked at a 17to 18-fold induction above background levels (Table 1A). The highest levels of the $b c d$ expression plasmid that were assayed resulted in lower increases in CAT activity, possibly due to a squelching effect (Gill and Ptashne 1988). These results suggest that the $b c d$ protein binds to one or more of the sites present in the stripe 2 sequences and activates transcription.

Similar experiments were performed with an expression plasmid (pAct5C- $h b$ ) containing the full-length $h b$ coding sequence. Increasing amounts of $h b$ resulted in only modest increases in CAT activity (Table 1B). However, coexpression of the $h b$ plasmid along with $b c d$ resulted in multiplicative activation, with as much as a 44-fold stimulation in CAT activity (Table 1C). An im- portant implication of this result is that the $b c d$ morphogen might regulate gene expression in early embryos by interacting with the $h b$ protein (see Discussion).

\section{Repression by $\mathrm{Kr}$ and gt requires DNA binding}

Cotransfection of $\mathrm{Kr}$ or $g t$ expression plasmids either abolished or markedly reduced the multiplicative activation obtained with $b c d$ and $h b$ (Tables 2 and 3). In these experiments amounts of the $b c d$ and $h b$ expression plasmids were used that resulted in peak (44-fold) activation of the reporter plasmid. Cotransfections with increasing amounts of a pAct5C-Kr expression plasmid caused as much as a 22 -fold reduction in the activation mediated by $b c d+h b$ (Table $2 \mathrm{~A}$ ). A significant reduction in CAT activity was obtained with only $0.2 \mu \mathrm{g}$ of the $K r$ expression plasmid, which is equivalent to the amount of $h b$ and just twofold more than the $b c d$ required for peak activation.

Similar cotransfection experiments done with a 


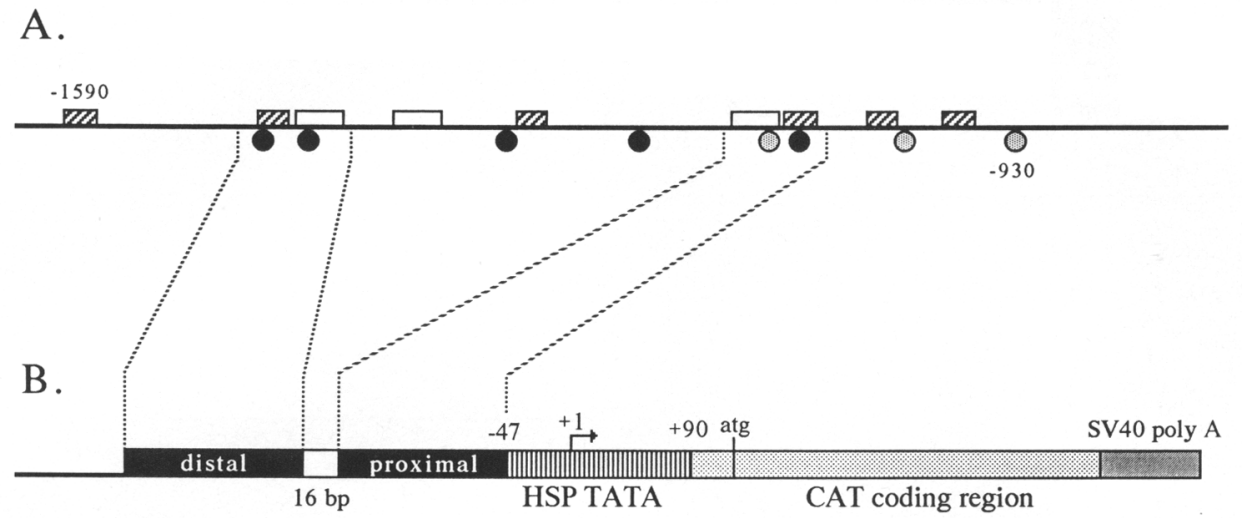

Figure 5. Schematic of CAT gene fusion construct used for cotransfection assays. The relationship of the binding sites within the stripe 2 element $(A)$ to the CAT gene fusion construct $(B)$ is shown. The reporter contains a 137-bp region of the Drosophila hsp 70 gene, which includes $47 \mathrm{bp}$ of the immediate 5 -flanking region and a 90-bp untranslated sequence. This minimal hsp 70 promoter was attached to the bacterial CAT-coding sequence, which is flanked at its $3^{\prime}$ end by SV40 polyadenylation sequences. A single copy of each cluster of binding sites was fused in tandem upstream of the minimal HSP70 promoter (see Materials and methods). These two clusters are separated by $16 \mathrm{bp}$ of sequences from the polylinker.

pAct5C-gt expression plasmid suggest that $g t$ is an even more effective repressor of stripe 2 expression than $K r$ (Table 3A). The use of an equivalent amount of the $g t$ expression plasmid nearly abolished $b c d-h b$ activation, reducing CAT activity to the same background level as that obtained in the absence of expression plasmids.

Even though $\mathrm{Kr}$ - and $g t$-binding sites are closely linked to $b c d$ and $h b$ activation sites within the stripe 2 element (see summary of sequence in Fig. 4B), the experiments outlined above do not rule out the possibility that repression involves a nonspecific squelching mechanism (Levine and Manley 1989). To exclude this possibility we analyzed the activities of mutant $K r$ and $g t$ proteins that are unable to bind DNA.

A mutant form of the $K r$ protein was synthesized (see Materials and methods) that mimics the product encoded by a null mutation in the gene, called $K r^{9}$ (Redemann et al. 1988). $K r^{9}$ is stably expressed in homozygotes and is identical to the wild-type protein except for a single amino acid substitution; one of the highly conserved cysteine residues in the second zinc finger is substituted with a serine (Rosenberg et al. 1986; Redemann et al. 1988; Fig. 6A). Such a substitution probably prevents the binding of $\mathrm{Zn}^{2+}$ atom, thereby disrupting the "finger" structure and impairing its ability to bind DNA (Rhodes and Klug 1988). Gel-shift assays indicate that the mutant $K r^{9}$ protein fails to bind to either $K r$ site contained in the reporter plasmid (data not shown). When tested in cotransfection assays, the $K r^{9}$ protein was unable to repress the multiplicative activation mediated by the $b c d$ and $h b$ proteins (Table $2 B$ ). Even the highest levels of the $K r^{9}$ expression plasmid that were assayed failed to reduce CAT expression. To assure that this lack of repression was not due to instability of the mutant protein, we compared the expression of the $K r^{9}$ protein to wild-type $K r$ in parallel cotransfection experiments by immunofluorescence staining (Fig. 6B). The two proteins are expressed at comparable levels. More- over, both proteins are restricted to nuclei, indicating that the amino acid substitution in the $K r^{9}$ protein does not disrupt normal nuclear transport.

In a similar series of experiments a mutant form of the $g t$ protein (gt B.4) was synthesized and tested. gt B.4 contains 2 amino acid changes in the basic region that is adjacent to the leucine zipper present near the carboxyl terminus (Fig. 6C). It has been suggested that this basic region supplies the contact points necessary for DNA binding via the "scissors-grip" model (Vinson et al. 1989|. When produced in a bacterial expression system, the mutant gt protein fails to bind to either site in the reporter plasmid (data not shown). In transient cotransfection assays, the gt B.4 protein also failed to repress CAT activation mediated by $b c d$ and $h b$ (Table 3B). Immunofluorescence experiments showed that the gt B.4 protein was stably expressed in nuclei (Fig. 6D), excluding the possibility that the failure to repress was due to problems of stability or intracellular transport. This experiment suggests that direct DNA binding is required for $g t$-mediated repression in this assay.

\section{Discussion}

We have presented a model for the initiation of eve stripe 2 , whereby the maternal morphogen $b c d$ and the gap protein $h b$ together define a broad activation domain in the anterior third of the embryo. The borders of the stripe depend on selective repression by the gap protein $g t$ in anterior regions and $K r$ protein in posterior regions. Previous studies have established that the normal spatial and temporal limits of $b c d, h b, K r$, and gt expression are closely linked with the stripe 2 pattern (Stanojevic et al. 1989; Warrior and Levine 1990; Kraut and Levine, 1991). Here, we provide additional evidence that these regulatory factors directly regulate stripe 2 expression, as summarized in Figure 1D. First, the borders of an eve-lacZ fusion gene that selectively expresses stripe 2 are ex- 
Table 1. bcd and hb activate CAT via the proximal/distal clusters of binding sites

A. bcd alone

\begin{tabular}{lrrrr}
\hline$b c d(\mu \mathrm{g})$ & CAT & & $h b(\mu \mathrm{g})$ & $\mathrm{CAT}$ \\
\hline 0.0 & 1.0 & 0.0 & 1.0 \\
0.01 & 5.2 & & 0.01 & 1.6 \\
0.025 & 10.4 & 0.025 & 2.6 \\
0.05 & 12.0 & 0.05 & 3.0 \\
0.1 & 16.9 & 0.1 & 3.8 \\
0.2 & 16.1 & 0.2 & 4.4 \\
0.4 & 17.6 & 0.4 & 4.5 \\
0.8 & 12.8 & 0.8 & 4.2 \\
1.6 & 12.6 & 1.6 & 2.0 \\
\hline
\end{tabular}

C. bed plus hb

\begin{tabular}{llr}
\hline$b c d(\mu \mathrm{g})$ & $h b(\mu \mathrm{g})$ & CAT \\
\hline 0.0 & 0.0 & 1.0 \\
0.01 & 0.01 & 12.0 \\
0.01 & 0.025 & 15.5 \\
0.01 & 0.05 & 16.3 \\
0.025 & 0.025 & 23.1 \\
0.025 & 0.05 & 28.6 \\
0.025 & 0.1 & 32.6 \\
0.05 & 0.05 & 32.0 \\
0.05 & 0.1 & 36.8 \\
0.05 & 0.2 & 41.9 \\
0.1 & 0.05 & 30.5 \\
0.1 & 0.1 & 36.3 \\
0.1 & 0.2 & 44.2 \\
\hline
\end{tabular}

Transient cotransfection assays were performed as described in Materials and Methods. Increasing amounts of the pAct5C-bcd expression plasmid $(A)$, the pAct5C- $h b$ plasmid $(B)$, or both $(C)$ were used along with $1.0 \mu \mathrm{g}$ of HSP-CAT reporter construct containing one copy each of the 51-bp distal element and one copy of the 54-bp proximal element in tandem (see Fig. 5). pAct5C plasmid (without insert) was added where necessary so that the total amount of expression plasmid was the same in each transfection. The CAT activities shown are relative amounts compared to the baseline activity obtained with the pAct5C plasmid alone (line 1 of $A-C$ ).

panded when crossed into $\mathrm{gt}^{-}$or $\mathrm{Kr}^{-}$embryos. Moreover, DNA-binding experiments indicate that $b c d, h b$, $K r$, and $g t$ proteins bind with high affinity to sequences contained within the stripe 2 promoter element. Finally, we have shown that $\sim 100 \mathrm{bp}$ of stripe 2 promoter sequences mediate activation by $b c d$ and $h b$ proteins and repression by $g t$ and $K r$.

\section{Does bcd directly regulate eve expression?}

The identification of multiple, high-affinity $b c d$-binding sites in the stripe 2 element suggests that the $b c d$ morphogen could play a direct role in activating eve expression in early embryos. Three of these binding sites mediate strong activation by the $b c d$ protein in cotransfection assays. The possibility that $b c d$ directly regulates $e v e$ challenges the strictest interpretation of the segmen-
Table 2. The CAT activation mediated by bcd and $\mathrm{hb}$ is repressed by wild-type $\mathrm{Kr}$ protein but not by $\mathrm{Kr}^{9}$

A. $\mathrm{Kr}$

\begin{tabular}{lccr}
\hline$b c d(\mu \mathrm{g})$ & $h b(\mu \mathrm{g})$ & $K r(\mu \mathrm{g})$ & $\mathrm{CAT}$ \\
\hline 0.1 & 0.2 & 0.0 & 44.2 \\
0.1 & 0.2 & 0.05 & 33.6 \\
0.1 & 0.2 & 0.2 & 11.6 \\
0.1 & 0.2 & 0.8 & 2.0 \\
\hline
\end{tabular}

B. $\mathrm{Kr}^{9}$

\begin{tabular}{lccc}
\hline$b c d(\mu \mathrm{g})$ & $h b(\mu \mathrm{g})$ & $K r^{9}(\mu \mathrm{g})$ & $\mathrm{CAT}$ \\
\hline 0.1 & 0.2 & 0.0 & 44.2 \\
0.1 & 0.2 & 0.05 & 45.8 \\
0.1 & 0.2 & 0.2 & 53.1 \\
0.1 & 0.2 & 0.8 & 47.8 \\
\hline
\end{tabular}

Cotransfections were done with $0.1 \mu \mathrm{g}$ of pAct $5 \mathrm{C}-$-bcd expression plasmid and $0.2 \mu \mathrm{g}$ of pAct $5 \mathrm{C}-h b$ along with increasing amounts of pAct $5 \mathrm{C}-\mathrm{Kr}(A)$ or pAct $5 \mathrm{C}-\mathrm{Kr}^{9}(B)$ and $1.0 \mu \mathrm{g}$ of the HSP-CAT reporter construct shown in Fig. 5.

tation hierarchy as a linear series of gene interactions. However, although our results are consistent with a direct role for $b c d$, it is conceivable that $b c d$ acts indirectly on stripe 2 expression via $h b$. It should be noted that there is a precedent for the direct involvement of a maternal factor with a pair-rule promoter: The so-called zebra element of the fushi tarazu (ftz) promoter (Hiromi et al. 1985) appears to be directly activated by the homeo box protein caudal (cad) (Dearolf et al. 1989).

The demonstration that combinations of the $b c d$ and $h b$ proteins can multiplicatively activate a reporter gene containing stripe 2 sequences suggests that $b c d$ might not influence the segmentation pattern solely through the regulation of gap genes. Previous studies have shown that the $b c d$ protein is distributed in a broad concentra-

Table 3. The CAT activation mediated by bcd and hb is repressed by wild-type gt protein but not by gt $B .4$

A. gt

\begin{tabular}{lclr}
\hline$b c d(\mu \mathrm{g})$ & $h b(\mu \mathrm{g})$ & $g t(\mu \mathrm{g})$ & $\mathrm{CAT}$ \\
\hline 0.1 & 0.2 & 0.0 & 44.2 \\
0.1 & 0.2 & 0.05 & 9.1 \\
0.1 & 0.2 & 0.2 & 1.2 \\
0.1 & 0.2 & 0.8 & 0.7 \\
\hline
\end{tabular}

B. gt $B .4$

\begin{tabular}{lccc}
\hline$b c d(\mu \mathrm{g})$ & $h b(\mu \mathrm{g})$ & $g t$ B.4 $(\mu \mathrm{g})$ & $\mathrm{CAT}$ \\
\hline 0.1 & 0.2 & 0.0 & 44.2 \\
0.1 & 0.2 & 0.05 & 42.3 \\
0.1 & 0.2 & 0.2 & 43.9 \\
0.1 & 0.2 & 0.8 & 40.2 \\
\hline
\end{tabular}

Cotransfections were done as in Table 2, except with increasing amounts of pAct5C-gt $(A)$ or pAct5C-gt B.4 $(B)$. 
A.

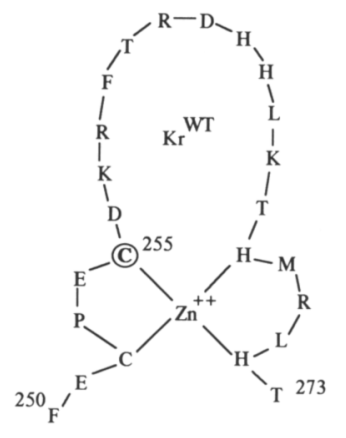

B.

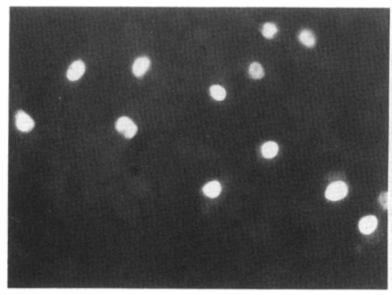

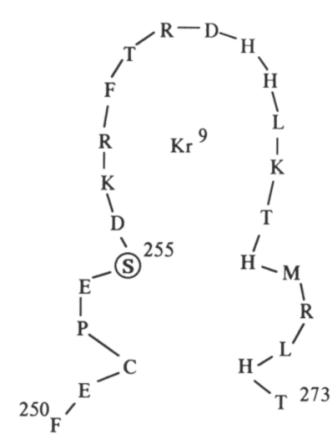

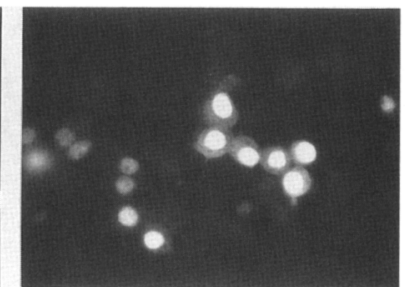

C.

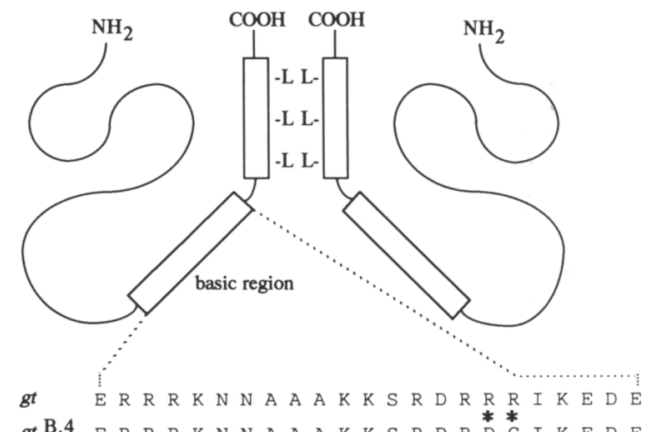

D.

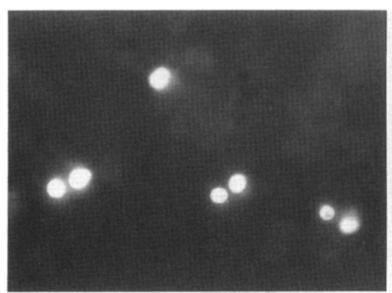

Figure 6. Summary of $K r$ and $g t$ proteins used in cotransfection assays. $(A)$ Predicted structure of the second of four $\mathrm{Zn}^{2+}$ fingers in the wild-type (left) and $\mathrm{Kr}^{9}$ mutant (right) proteins (Redemann et al. 1988). Amino acid residues are represented by the single-letter code. $K \vec{r}^{9}$ containins a serine residue at position 255 in place of one of the highly conserved cysteine residues in the wild-type protein. This substitution should prevent the formation of a functional $\mathrm{Zn}^{2+}$ finger and impairs its ability to bind DNA (data not shown). $(B)$ Expression of the wild-type $(l e f t)$ and $K r^{9}$ (right) proteins in transfected Schneider cells. Both proteins are stably expressed in nuclei. Proteins were detected with anti- $K r$ antibodies and visualized by indirect immunofluorescence. $(C)$ Predicted structure of a $g t$ protein dimer by association of putative leucine zippers (after Landschulz et al. 1989). The sequence of the basic region adjacent to the leucine zipper is shown for the wild-type $g t$ protein and the synthetic mutant $g t$ B.4. (D) Expression of the wild-type (left) and the $g t$ B. 4 (right) proteins in transfected Schneider cells. Both proteins are stably expressed in nuclei.

tion gradient with peak levels at the anterior pole (Driever and Nüsslein-Volhard 1988). Only levels of $b c d$ protein above a minimal threshold can activate $h b$, resulting in a relatively sharp border of $h b$ expression in anterior regions (Driever et al. 1989; Struhl et al. 1989). This threshold process could, in principle, generate two distinct combinations of regulatory activity, with embryonic cells in anterior regions containing both the $b c d$ and $h b$ proteins while more posterior cells express only $b c d$. Several types of mechanisms could account for multiplicative interactions between the $b c d$ and $h b$ proteins, including cooperative binding to DNA or so-called "promiscuous" cooperativity involving protein-protein interactions with the transcription machinery (Lin et al. $1990 \mid$

\section{Mechanism of repression}

Genetic studies have shown that relatively small changes in the level of $K r$ protein cause a significant expansion in the limits of eve stripe 2 expression (Frasch and Levine 1987; Warrior and Levine 1990/. Thus, the broad, bell-shaped distribution profile of $K r$ expression in central regions of the embryo dictates a relatively sharp on/off switch in eve expression (see Fig. 1D). Although the $K r$ expression pattern has not been quantified, it would appear that on the order of a twofold change in the level of repressor is sufficient to trigger this switch. Such threshold repression might be a manifestation of cooperativity between activators. Three of the five $b c d$-binding sites present within the stripe 2 element are closely linked to a $K r$ site. In principle, $K r$ might repress expression by competing with the binding of $b c d$ to just one or two of the sites, as this would disrupt potential cooperative interactions among the activators.

A related mechanism of repression is that the binding of $g t$ or $K r$ to a given site interferes with the activity, but not the binding, of neighboring $b c d$ proteins. For example, $g t$ bound to the proximal cluster should block the binding of the $h b$ activator (see Fig. 4B). Perhaps gt also represses by masking or "quenching" the activity of $b c d$ bound at the neighboring site (Levine and Manley 1989).

Transient cotransfection assays suggest that $g t$ is a more effective repressor than $K r$ (see Tables 2 and 3). The greater effectiveness of $g t$ reflects the situation in the embryo, in that $g t$ is active in regions where there are higher levels of the $b c d$ and $h b$ activators (see Fig. 1D). In contrast, as discussed above, $K r$ is active in regions containing only low levels of these activators. It should be noted, however, that repression by $g t$ is not sufficient to account for the establishment of the stripe 2 border in vivo. There is a transient and incomplete fusion of 
stripes 1 and 2 in $\mathrm{gt}^{-}$embryos (Frasch and Levine 1987), raising the possibility that additional repressors operate to keep the stripe 2 element off in anterior regions containing high levels of the $b c d$ and $h b$ activators.

\section{Short-range repression permits autonomous action of stripe elements}

The eve promoter is composed of a series of separate cis sequences that regulate individual stripes, although all of these elements act on a common promoter. How do these elements act independently of one another? A similar situation has been shown for the hairy promoter, which is another primary pair-rule gene containing separate stripe initiation elements (Howard et al. 1988; Howard and Struhl 1990; Pankratz et al. 1990).

The summary figure shown in Figure 7 presents a model that describes how two stripe initiation elements, 2 and 3 , might function autonomously. Genetic studies on the regulation of stripe 3 are incomplete, but a reasonable possibility is that $h b$ (and perhaps $b c d$ ) both activates and represses its expression (Frasch and Levine 1987; R. Warrior and M. Levine, unpubl.). Approximately $20 \mathrm{hb}$-binding sites have been identified within the stripe 3 element, which might permit its activation in regions of the embryo where there are low levels of the $h b$ protein (Stanojevic et al. 1989). Activation might occur when a small number of high-affinity $h b$-binding sites are filled. In more anterior regions there are high levels of $h b$, which might result in binding to most or all of the sites, including low-affinity sites that mediate repression. Transient cotransfection assays are consistent with this model and have shown that $h b$ can activate or repress gene expression in a concentration-dependent manner (Zuo et al. 1991). The stripe 3 element might evade repression by even high concentrations of the $K r$ repressor, as it completely lacks high-affinity $K r$-binding sites (Stanojevic et al. 1989). In regions where stripe 3 is expressed the stripe 2 element is inactive due to the binding of $K r$ protein to the three high-affinity sites it contains.

An important implication of this model is that the binding of $K r$ to the stripe 2 element does not interfere with the activity of the stripe 3 element, which is located $\sim 1.5 \mathrm{~kb}$ away (Goto et al. 1989; Harding et al. 1989; see summary in Fig. 2A). The inability of $K r$ to repress over such a distance is compatible with the cotransfection studies, which suggest that short-range repression is sufficient to account for the inactivation of stripe 2 expression. It is striking that nearly every one of the $b c d$-and $h b$-binding sites present within the stripe 2 element overlaps or is immediately adjacent to a $g t$ or $K r$ repressor site. If long-range repression were an important mechanism governing eve expression, there would be no need to have such tight linkage of the activators and repressors. Similar arrangements of activators and repressors have been identified in numerous mammalian promoters, which suggests that short-range repression might be important in these systems as well (Maniatis et al. 1987). Short-range repression might account for the evolution of complex promoters that are composed of multiple, autonomous regulatory elements.

\section{Materials and methods}

\section{Recombinant plasmids}

The eve stripe 2 element/heat shock promoter (HSP)/CAT reporter plasmid (Fig. 5) was constructed from synthetic oligonucleotides (sequences are shown in Fig. 4C). Each oligonucleotide set was annealed together, blunt-ended with Klenow, and
Figure 7. A model for the autonomous action of the stripe 2 and 3 elements. The curves represent, only very approximately, the limits and levels of $b c d, h b$ and $K r$ expression in the region of the embryo where eve stripes 2 and 3 are expressed. The dashed vertical lines correspond to the stripe 2 and 3 borders. The region of stripe 2 expression contains relatively high levels of $b c d$ and $h b$ and low levels of $K r$. In contrast, the region of stripe 3 expression contains low levels of $b c d$ and $h b$ expression and very high levels of $K r$. The horizontal lines on the bottom represent the activities of the eve promoter in regions of the embryo where stripes 2 and 3 are expressed. In the stripe 2 region many $b c d$ - and $h b$-binding sites in the eve promoter are occupied (lower left), resulting in the activation of the stripe 2 element and the repression of the 3 element. Repression of the stripe 3 element might result from the binding of $h b$ (and/or $b c d$ ) to low-affinity sites that mediate repression (see Discussion). In the stripe 3 region the high concentrations of $K r$ repress the stripe 2 element, but not the stripe 3 element, because it lacks $K r$-binding sites (Stanojevic et al. 1989). The lower levels of $h b$ (and perhaps $b c d$ ) in this region might activate the stripe 3 element by binding only to high-affinity sites (see Discussion).

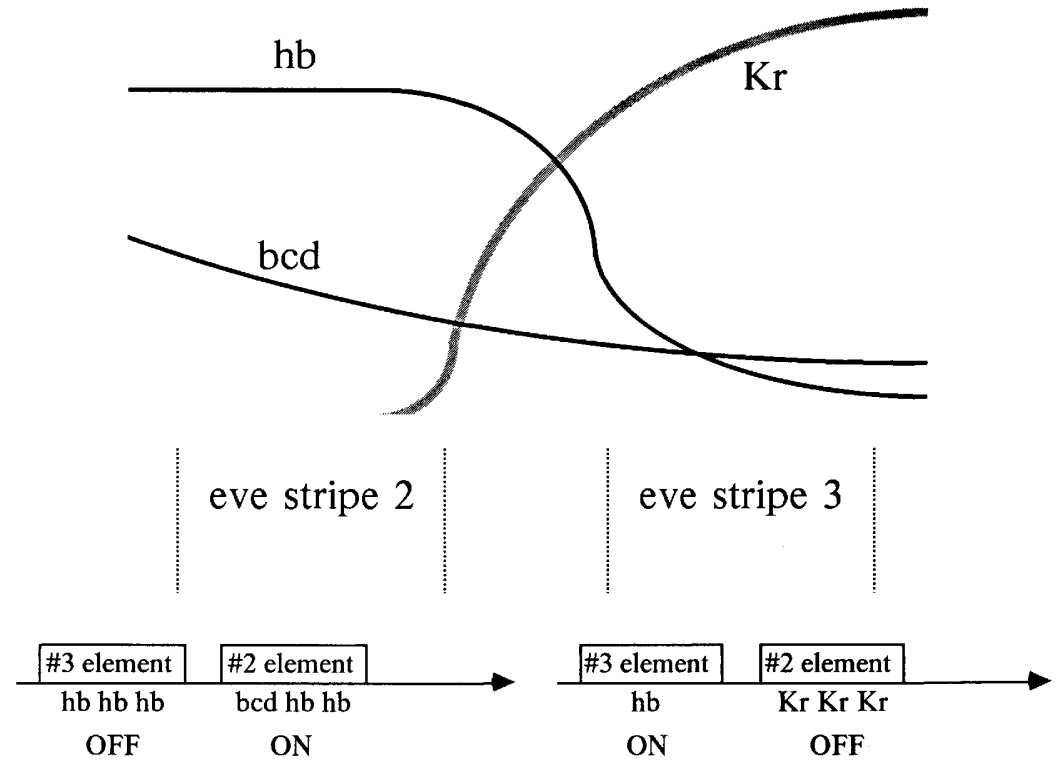


cloned separately into the EcoRV site of pBluescript SK - (purchased from Strategene, La Jolla, CA) to generate intermediate clones pBS51 and pBS54. The 51-bp distal element was cloned upstream of the 54-bp proximal element by cutting pBS51 with EcoRI, blunt-ending, and cutting with KpnI to give a 90-bp fragment, which was ligated into pBS54 that was cut with HindIII, blunt-ended, and cut with KpnI. This clone (pBS51/54) was sequenced to verify that it contained both elements separated by 16 bases of Bluescript polylinker. pBS51/54 was then cut with EcoRI, blunt-ended, cut with HindIII, and inserted into HSPCAT parental vector that had been cut with SalI, blunt-ended, and cut with HindIII. The promoter sequences from the stripe 2 region were also cloned into another CAT vector that contains the metallothionine minimal promoter in place of the HSP70 sequences (Han et al. 1989). In all cases, the two different basal promoters gave very similar results.

The $b c d$ expression vector pAct5C-bcd was prepared by cloning the NdeI-BamHI fragment containing the $b c d$-coding region from pAR-bcdNB (Driever and Nüsslein-Volhard 1989) into $\mathrm{pPacU}+\mathrm{NDE}$ (Biggin and Tjian 1989). This bcd protein contains two extra residues at the amino terminus (methionine and histidinel. All other expression vectors were derived from the parental plasmid pAct5CSRS, kindly provided by Dr. K. Burgess. This plasmid contains $\sim 2.5 \mathrm{~kb}$ of $5^{\prime}$-flanking sequences from the Drosophila actin 5C gene. pAct5C-gt was constructed from a full-length $g t$ cDNA (described by Kraut and Levine 1991). pAct5C-hb and pAct5C- $K r$ were kindly provided by K. Han (see Zuo et al. 1991). To make the pAct5C $-K r^{9}$ expression plasmid, a $\sim 1500$-bp NotI-KpnI fragment from the $K r$-coding sequence was cloned into the polylinker of pBluescript SK-. The $K r^{9}$ mutation was generated by oligonucleotide-directed mutagenesis by using the 31-nucleotide oligomer, 5'-GAATGTCCGGGGAAAGTGACAAGCGGTTTAC-3', which contains three mismatches with the wild-type $K r$ sequence. These substitutions change a cysteine residue to a serine laccording to the sequence of the $K r^{9}$ mutant reported by Redemann et al. 1988). Mutagenic clones were screened by sequence analysis. The 1500-bp NotI-KpnI-mutagenized fragment was then substituted back into the parent vector pAct $5 \mathrm{C}-K r$, verified by restriction mapping and sequence analysis. The $g t$ B.4 mutation was generated by oligonucleotide-directed mutagenesis by using the 30-nucleotide oligomer 5'-GAACTACGCCGGCAGTAGCGCCCTGAAGAA- $3^{\prime}$, which contains three mismatches with the wild-type sequence ( $R$. Kraut, unpubl.). The 1.4-kb NdeI-SacI fragment containing the mutagenized sequence was then substituted back into the parental vector pAct5C-gt and verified by restriction and sequence analysis.

\section{DNase I protection assays}

Footprint assays were performed exactly as described by Hoey and Levine (1988). Protein extracts used for the binding assays with $K r$ and $g t$ were prepared with guanidine $\mathrm{HCl}$, followed by extensive dialysis, exactly as described by Hoey et al. (1988). The $b c d$ protein used in the DNA-binding studies was affinity purified from the soluble fraction of the bacterial lysate essentially as described (Kadonaga and Tjian 1986) by using multimers of the A $3 b c d$-binding site from the $h b$ promoter (Driever and Nüsslein-Volhard 1989).

\section{Antibody staining of embryos}

$P$ transformants were stained with a rabbit anti- $\beta$-galactosidase and detected by a histochemical procedure employing the $\mathrm{ABC}$ Elite kit (purchased from Vector Labs, Burlingame, CA), exactly as described by the manufacturer. The stained embryos were photographed, and the color transparencies were used to print the inverse image, as described by Harding et al. (1989). Immunolocalization of $e v e$ was done with a rabbit anti-eve antibody, kindly provided by Dr. Manfred Frasch. gt was detected with a guinea pig antibody described by Kraut and Levine (1991), $\mathrm{Kr}$ was localized with a rabbit anti-Kr antibody kindly provided by Dr. Christine Rushlow, and $h b$ was detected with a mouse antibody kindly provided by David Kosman. Double immunofluorescence staining was done exactly as described by Stanojevic et al. (1989).

\section{Cotransfections and transient expression assays}

Drosophila Schneider S2M3 cells were grown in M3 medium (GIBCO) supplemented with $10 \%$ defined fetal bovine serum (GIBCO), which was heat inactivated at $60^{\circ} \mathrm{C}$ for $30 \mathrm{~min}$. Cotransfections were performed essentially as reported in Han et al. (1989). For each transfection $\sim 4 \times 10^{6}$ cells were plated per $60-\mathrm{mm}$ tissue culture dish 1 day before transfection. In all cases, $1.0 \mu \mathrm{g}$ of a given eve element/HSP/CAT reporter plasmid was transfected along with various amounts of expression plasmids and $2.0 \mu \mathrm{g}$ of Copia long-terminal repeat (LTR)-lacZ plasmid, which served as an internal control for transfection efficiency (Han et al. 1989). pAct5C plasmid vector (without inserted coding sequences) was added where required to standardize the amount of expression plasmids in each experiment. The total amount of DNA in each transfection was adjusted to $10 \mu \mathrm{g}$ by the addition of pGEM-1 or pUC18 as carrier. All experiments were performed at least twice. Preparations of cell extracts, $\beta$-galactosidase assays, and CAT assays were described previously (Han et al. 1989). Indirect immunofluorescence assays were performed as described by Rushlow et al. (1989). For the $K r$ experiments a rabbit anti-Kr primary antibody and a TRITC-conjugated anti-rabbit secondary antibody were used to detect $K r$ protein. For the gt experiments a guinea pig anti-gt antibody and a TRITC-conjugated anti-guinea pig secondary antibody were used to detect $g t$ protein.

\section{Acknowledgments}

We thank Dr. Wolfgang Driever for the pARbcdNB expression plasmid and Peter Lawrence for help with rewriting the manuscript. We are grateful to $\mathrm{K}$. Han and J. Colgan for assistance with the cotransfection assays. We also thank Denise Boyd for technical assistance. We are grateful to Robert Tjian for permitting T.H. to perform the footprint assays in his laboratory. This work was funded by a grant from the National Institutes of Health (GM 34431).

The publication costs of this article were defrayed in part by payment of page charges. This article must therefore be hereby marked "advertisement" in accordance with 18 USC section 1734 solely to indicate this fact.

\section{References}

Akam, M. 1987. The molecular basis for metameric pattern formation in the Drosophila embryo. Development 101: 122.

Berleth, T., M. Burri, G. Thoma, D. Bopp, S. Richstein, G. Frigerio, M. Noll, and C. Nüsslein-Volhard. 1988. The role of localization of bicoid RNA in organizing the anterior pattern of the Drosophila embryo. EMBO J. 7: 1749-1756.

Biggin, M. D. and R. Tjian. 1989. A purified Drosophila homeodomain protein represses transcription in vitro. Cell 58: $433-440$. 
Dearolf, C., J. Topol, and C. Parker. 1989. Transcriptional control of Drosophila fushi tarazu zebra stripe expression. Genes \& Dev. 3: 384-398.

Dinardo, S., I. Kuner, J. Theis, and P. O'Farrell. 1985. Development of embryonic pattern in $\mathrm{D}$. melanogaster as revealed by accumulation of the nuclear engrailed protein. Cell 43: 5969.

Driever, W. and C. Nüsslein-Volhard. 1988. A gradient of bicoid protein in Drosophila embryos. Cell 54: 83-93.

Driever, W. and C. Nüsslein-Volhard. 1989. The bicoid protein is a positive regulator of hunchback transcription in the early Drosophila embryo. Nature 337: 138-143.

Driever, W., G. Thoma, and C. Nüsslein-Volhard 1989. Determination of spatial domains of zygotic gene expression in the Drosophila embryo by the affinity of binding sites for the bicoid morphogen. Nature 340: 363-367.

Frasch, M. and M. Levine. 1987. Complementary patterns of even-skipped and fushi tarazu expression involve their differential regulation by a common set of segmentation genes in Drosophila. Genes \& Dev. 1: 981-995.

Frasch, M., R. Warrior, J. Tugwood, and M. Levine. 1988. Molecular analysis of even-skipped mutants in Drosophila development. Genes \& Dev. 2: 1824-1838.

Frasch, M., T. Hoey, C. Rushlow, H. Doyle, and M. Levine. 1987. Characterization and localization of the even-skipped protein of Drosophila. EMBO J. 6: 749-759.

Gaul, U. and H. Jackle. 1987. Pole region-dependent repression of the Drosophila gap gene Krüppel by maternal gene products. Cell 51: 549-555.

Gill, G. and M. Ptashne. 1988. Negative effect of the transcriptional activator GAL4. Nature 330: 721-724.

Goto, T., P. Macdonald, and T. Maniatis. 1989. Early and late periodic patterns of even-skipped expression are controlled by distinct regulatory elements that respond to different spatial cues. Cell 57: 413-422.

Han, K., M. Levine, and J. Manley. 1989. Synergistic activation and repression of transcription by Drosophila homeobox proteins. Cell 56: 573-583.

Harding, K., C. Rushlow, H. Doyle, T. Hoey, and M. Levine. 1986. Cross-regulatory interactions among pair-rule genes in Drosophila. Science 233: 953-959.

Harding, K., T. Hoey, R. Warrior, and M. Levine. 1989. Autoregulatory and gap response elements of the even-skipped promoter of Drosophila. EMBO /. 8: 1205-1212.

Hiromi, Y. and W.J. Gehring. 1987. Regulation and function of the Drosophila segmentation gene fushi tarazu. Cell 50: $963-971$.

Hiromi, Y., A. Kuroiwa, and W.J. Gehring. 1985. Control elements of the Drosophila segmentation gene fushi tarazu. Cell 43: 603-613.

Hoey, T. and M. Levine. 1988. Divergent homeo box proteins recognize similar DNA sequences in Drosophila. Nature 331: 858-861.

Hoey, T., R. Warrior, J. Manak, and M. Levine. 1988. DNAbinding activities of the Drosophila melanogaster evenskipped protein are mediated by its homeo domain and influenced by protein context. Mol. Cell. Biol. 8: 4598-4607.

Hooper, J.E. and M.P. Scott. 1989. The Drosophila patched gene encodes a putative membrane protein required for segmental patterning. Cell 59: 751-765.

Howard, K.R. and G. Struhl. 1990. Decoding positional information: Regulation of the pair-rule gene hairy. Development 110: 1223-1231.

Howard, K., P. Ingham, and C. Rushlow. 1988. Region-specific alleles of the Drosophila segmentation gene hairy. Genes \& Dev. 2: 1037-1046.
Ingham, P. 1988. The molecular genetics of embryonic pattern formation in Drosophila. Nature 335: 25-34.

Jiang, J., T. Hoey, and M. Levine. 1991. Autoregulation of a segmentation gene in Drosophila: Combinatorial interaction of the even-skipped homeo box protein with a distal enhancer element. Genes \& Dev. 5: 265-277.

Kadonaga, J.T. and R. Tjian. 1986. Affinity purification of sequence-specific DNA binding proteins. Proc. Natl. Acad. Sci. 83: 5889-5893.

Kaufman, T., R. Lewis, and B.T. Wakimoto. 1980. Cytogenetic analysis of chromosome 3 in Drosophila melanogaster: The homeotic gene complex in polytene chromosome interval 84A-B. Genetics 94: 115-133.

Kornberg, T., I. Siden, P. O'Farrell, and M. Simon. 1985. The engrailed locus of Drosophila: In situ localization of transcripts reveals compartment-specific expression. Cell 40: $45-53$.

Kraut, R. and M. Levine. 1991. Spatial regulation of the gap gene giant during Drosophila development. Development 111: 601-609.

Landschulz, W.H., P.F. Johnson, and S.L. McKnight. 1989. The DNA domain of the rat liver nuclear protein C/EBP is bipartite. Science 243: 1681-1688.

Laughon, A. and M.P. Scott. 1984. Sequence of a Drosophila segmentation gene: Protein structure homology with DNAbinding proteins. Nature 310: 25-31.

Lawrence, P., P. Johnston, P. Macdonald, and G. Struhl. 1987. Borders of parasegments in Drosophila are delimited by the fushi tarazu and even-skipped genes. Nature 328: 440-442.

Levine, M. and J.L. Manley. 1989. Transcriptional repression of eukaryotic promoters. Cell 59: 405-408.

Levine, M. and T. Hoey. 1988. Homeobox proteins as sequencespecific transcription factors. Cell 55: $537-540$.

Lewis, E.B. 1978. A gene complex controlling segmentation in Drosophila. Nature 276: 565-570.

Licht, J., M. Grossel, J. Figge, and U. Hansen. 1990. Drosophila Krüppel protein is a transcriptional repressor. Nature 346: 76-79.

Lin, Y., M. Carey, M. Ptashne, and M. Green. 1990. How different eukaryotic transcriptional activators can cooperate promiscuously. Nature 345: 359-361.

Macdonald, P., P. Ingham, and G. Struhl. 1986. Isolation, structure, and expression of even-skipped: A second pair-rule gene of Drosophila containing a homeo box. Cell 47: 721734.

Maniatis, T., S. Goodbourn, and J. Fischer. 1987. Regulation of inducible and tissue-specific gene expression. Science 236: $1237-1244$.

McGinnis, W., R. Garber, J. Wirz, A. Kuroiwa, and W.J. Gehring. 1984. A homologous protein-coding sequence in Drosophila homeotic genes and its conservation in other metazoans. Cell 37: 403-408.

Mohler, J., E. Eldon, and V. Pirotta. 1989. A novel transcription pattern associated with the segmentation gene, giant, of Drosophila. EMBO I. 8: 1539-1548.

Murre, C., P. McCaw, and D. Baltimore. 1989. A new DNA binding and dimerization motif in immunoglobulin enhancer binding, daughterless, MyoD, and myc proteins. Cell 56: 777-783.

Nakano, Y., A. Guerrero, A. Hidalgo, A. Taylor, J.R.S. Whittle, and P.W. Ingham. 1989. A protein with several possible membrane-spanning domains encoded by the Drosophila segment polarity gene patched. Nature 341: 508-513.

Nüsslein-Volhard, C. and E. Wieschaus. 1980. Mutations affecting segment number and polarity in Drosophila. Nature 287: 795-801 
Pankratz, M., E. Seifert, N. Gerwin, B. Billi, U. Nauber, and H. Jäckle. 1990. Gradients of Krüppel and knirps gene products direct pair-rule gene stripe patterning in the posterior region of the Drosophila embryo. Cell 61: 309-317.

Pignoni, F., R. Baldarelli, E. Steingrimsson, R. Diaz, A. Patapoutian, J. Merriam, and J. Lengyel. 1990. The Drosophila gene tailless is expressed at the embryonic termini and is a member of the steroid receptor superfamily. Cell 62: $151-163$.

Redemann, N., U. Gaul, and H. Jäckle. 1988. Disruption of a putative Cys-zinc interaction eliminates the biological activity of the Krüppel finger protein. Nature 332: 90-92.

Rhodes, D. and A. Klug. 1988. Zinc fingers: A novel motif for nucleic acid binding. In Nucleic acids and molecular biology. (ed. F. Ecksteinn, and D.J.M. Lilley), vol. 2. SpringerVerlag, Berlin.

Rosenberg, U., C. Schroder, A. Preiss, A. Kienlin, S. Cote, I. Riede, and H. Jäckle. 1986. Structural homology of the product of the Drosophila Krüppel gene with Xenopus transcription factor IIIA. Nature 319: 336-339.

Rushlow, C.A., K. Han, J.L. Manley, and M. Levine. 1989. The graded distribution of the dorsal morphogen is initiated by selective nuclear transport in Drosophila. Cell 59: 11651177.

Scott, M.P., J.W. Tamkun, and G.W. Hartzell III. 1989. The structure and function of the homeodomain. Biochim. Biophys. Acta 989: 25-48.

Stanojevic, D., T. Hoey, and M. Levine. 1989. Sequence-specific DNA-binding activities of the gap proteins encoded by hunchback and Krüppel in Drosophila. Nature 341: 331335.

Struhl, G. 1985. Near-reciprocal phenotypes caused by inactivation or indiscriminate expression of the Drosophila segmentation gene $f t z$. Nature 318: 677-680.

Struhl, G., K. Struhl, and P. Macdonald. 1989. The gradient morphogen bicoid is a concentration-dependent transcriptional activator. Cell 57: 1259-1273.

Studier, F. and B. Moffatt. 1986. Use of bacteriophage T7 RNA polymerase to direct selective high-level expression of cloned genes. J. Mol. Biol. 189: 113-130.

Tautz, D., R. Lehmann, H. Schnurch, R. Schuh, E. Seifert, A. Kienlin, K. Jones, and H. Jac̈kle. 1987. Finger protein of novel structure encoded by hunchback, a second member of the gap class of Drosophila segmentation genes. Nature 327: 383-389.

Treismann, J. and C. Desplan. 1989. The products of the Drosophila gap genes hunchback and Krüppel bind to the hunchback promoter. Nature 341: 335-337.

Vinson, C., P. Sigler, and S.L. McKnight. 1989. Scissors-grip model for DNA recognition by a family of leucine zipper proteins. Science 246: 911-916.

Warrior, R. and M. Levine. 1990. Dose-dependent regulation of pair-rule stripes by gap proteins and the initiation of segment polarity. Development 4: 759-767.

Wieschaus, E., C. Nüsslein-Volhard, and G. Jürgens. 1984. Mutations affecting the pattern of the larval cuticle in Drosophila melanogaster. III. Zygotic loci on the $\mathrm{X}$ chromosome and fourth chromosome. Wilhelm Roux's Arch. Dev. Biol. 193: $296-307$.

Zuo, P., D. Stanojevic, J. Colgan, K. Han, M. Levine, and J.L. Manley. 1991. Activation and repression of transcription by the Drosophila gap proteins hunchback and Krüppel. Genes \& Dev. 5: 254-264. 


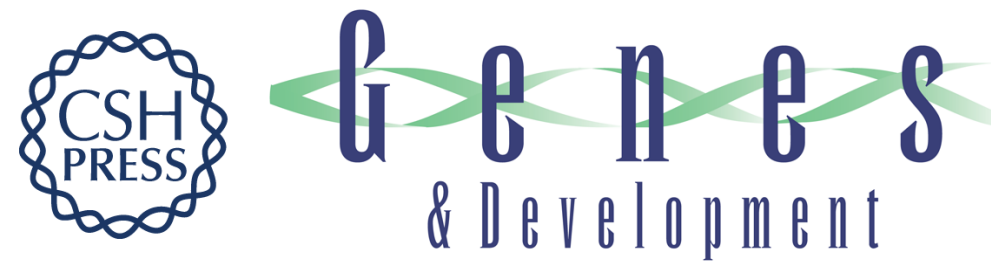

\section{Transcriptional regulation of a pair-rule stripe in Drosophila.}

S Small, R Kraut, T Hoey, et al.

Genes Dev. 1991, 5:

Access the most recent version at doi:10.1101/gad.5.5.827

References This article cites 61 articles, 16 of which can be accessed free at: http://genesdev.cshlp.org/content/5/5/827.full.html\#ref-list-1

License

Email Alerting

Receive free email alerts when new articles cite this article - sign up in the box at the top Service right corner of the article or click here.

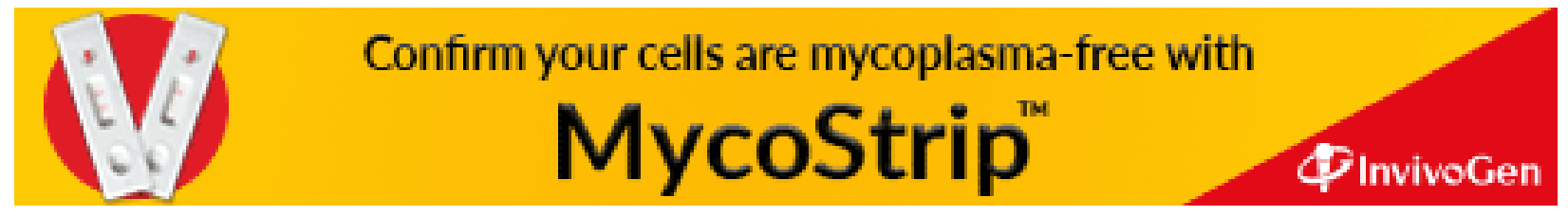

